\title{
Exploring Spray-Coating Techniques for Organic Solar Cell Applications
}

\author{
Wanyi Nie, ${ }^{1}$ Robert Coffin,, ${ }^{1}$ Jiwen Liu, ${ }^{1}$ Christopher M. MacNeill, ${ }^{2}$ Yuan Li, ${ }^{1}$ \\ Ronald E. Noftle, ${ }^{2}$ and David L. Carroll ${ }^{1}$ \\ ${ }^{1}$ Center for Nanotechnology and Molecular Materials, Wake Forest University, 501 Deacon Boulevard, \\ Winston-Salem, NC 27105, USA \\ ${ }^{2}$ Department of Chemistry, Wake Forest University, 1834 Wake Forest Road, Winston-Salem, NC 27109, USA
}

Correspondence should be addressed to David L. Carroll, carroldl@wfu.edu

Received 5 December 2011; Revised 5 March 2012; Accepted 7 March 2012

Academic Editor: Peter Rupnowski

Copyright (c) 2012 Wanyi Nie et al. This is an open access article distributed under the Creative Commons Attribution License, which permits unrestricted use, distribution, and reproduction in any medium, provided the original work is properly cited.

\begin{abstract}
We have investigated spray coating as a novel processing method for organic solar cell fabrication. In this work, spraying parameters and organic solvent influences have been correlated with cell performance. Using airbrush fabrication, bulk heterojunction photovoltaic devices based on a new low band gap donor material: poly[(4,8-bis(1-pentylhexyloxy)benzo[1,2b:4,5-b' $]$ dithiophene-2,6-diyl-alt-2,1,3-benzoxadiazole-4,7-diyl] with the C60-derivative (6,6)-phenyl C61-butyric acid methyl ester (PCBM) as an acceptor, have achieved power conversion efficiencies over $3 \%$. We show that airbrush fabrication can be carried out with simple solvents such as pristine 1,2-dichlorobenzene. Moreover, the influence of device active area has been studied and the $1 \mathrm{~cm}^{2}$ device by spray coating maintained an excellent power conversion efficiency of $3.02 \%$ on average.
\end{abstract}

\section{Introduction}

Worldwide, organic photovoltaics are under development as an inexpensive approach for collecting solar energy. Within the field, much effort has been given to the modification of either the absorber chemistry or its structural order. The chemical approach used by most researchers is to modulate the HOMO-LUMO levels of the donor polymer to obtain a low optical band gap $(<1.74 \mathrm{eV})$ and thereby allow for absorption in a range that best matches the solar spectrum [1]. Recently, significant progress has been achieved following these routes, from a starting efficiency of around $1 \%$ in 1995 [2] when the bulk-heterojunction architecture was introduced, to $5 \%$ in 2007 for the first low band gap donor polymer [3] and most recently record efficiencies of $6 \%$ $8 \%[4-6]$. However, these results are generally limited to the laboratory by the experimental requirement of using ultrathin layers that typically means employing spin coating. This method of fabrication only allows for devices on a small scale (usually $2.5 \mathrm{~cm} \times 2.5 \mathrm{~cm}$ chips) that would neither control the cost nor satisfy the needs of large-scale manufacturing. Because of this, alternative coating technologies for absorbers have been of significant interest, aimed specifically at cheap, large area coating. These have included ink-jet printing [7], roll-to-roll printing [8], brush painting [9], and spray coating $[10,11]$. Among these techniques, spray coating began to gain attention when Vak et al. in 2007 [12] showed they could easily fabricate the active layer with a commercially available hand-held airbrush. Up until now, most of the studies on spray coating OPV have been based on the poly(3hexyl thiophene) (P3HT): the $\mathrm{C}_{60}$-derivative $(6,6)$-phenyl C61-butyric acid methyl ester (PCBM) bulk-heterojunction (BHJ) material system and the commonly achieved efficiency was $2-3 \%$ with a small active area $\left(10 \mathrm{~mm}^{2}\right)$. Therefore, a natural question is "how will the low band gap polymers with higher efficiencies translate into these scalable techniques?"

Previously we reported a newly designed and synthesized low band gap polymer $(\sim 1.69 \mathrm{eV})$ poly [ $(4,8-b i s(1-$ pentylhexyloxy)benzo[1,2-b:4,5- $\left.b^{\prime}\right]$ dithiophene-2,6-diylalt-2,1,3-benzoxadiazole-4,7-diyl] (P1) [13]. When optimized with solvent additives in spin coating fabrication, this polymer easily achieves efficiencies exceeding $6 \%$. Based on a similar donoracceptor architecture as the record polymers referenced above, this polymer provides an excellent opportunity to 
TABLE 1: Average $J V$ characteristics by spraying coating. P1: PCBM solutions dissolved by CB, DCB and TCB under room temperature and spin coated from DCB. The maximum value of PCE over 8 devices under each condition is given in the last column as Peak PCE.

\begin{tabular}{lcccccc}
\hline & Solvent & Voc $(\mathrm{V})$ & Jsc $\left(\mathrm{mA} / \mathrm{cm}^{2}\right)$ & FF & PCE & Peak PCE \\
\hline \multirow{3}{*}{ Spray coating } & CB & 0.946 & 5.67 & 0.455 & $2.37 \%$ & $2.53 \%$ \\
& DCB & 0.960 & 6.88 & 0.404 & $2.68 \%$ & $3.00 \%$ \\
& TCB & 0.902 & 3.88 & 0.377 & $1.31 \%$ & $1.40 \%$ \\
\hline \multirow{2}{*}{ Spin coating } & CB & 0.978 & 2.58 & 0.564 & $1.38 \%$ & $1.42 \%$ \\
& DCB & 0.923 & 7.61 & 0.496 & $3.49 \%$ & $3.72 \%$ \\
\hline \multirow{2}{*}{ Spray coating P3HT } & Un-annealed & 0.628 & 4.59 & 0.316 & $0.91 \%$ & $2.5 \%$ \\
& Annealed & 0.624 & 9.39 & 0.426 & & $2.72 \%$ \\
\hline
\end{tabular}

study correlations in such systems, between spray-coating techniques and device performance for potential large scale applications.

\section{Experiment}

Prepatterned ITO substrates were cleaned in an ultrasonication bath with triton water, DI water, acetone, and isopropylalcohol for $20 \mathrm{~min}$ respectively and dried in a vacuum oven at $100^{\circ} \mathrm{C}$ for 1 hour. A $30 \mathrm{~min} \mathrm{UV}$-Ozone treatment was performed on the ITO surface afterwards and PEDOT: PSS (CLEVIOS 4083) was spun cast at a spin speed of $4000 \mathrm{rpm}$. The $100 \mathrm{~nm}$ active layer was either spun cast or spray-coated from the blend solution of P1 and PCBM (the optimized ratio of $1: 2$ by weight was previous determined by experiment and $I V$ curve available in Figure 4 in the appendix) dissolved in 1,2-dichlorobenzene (DCB). The substrates with dried films were transferred to a vacuum chamber, pumped down to $1 \times 10^{-6}$ torr and $\operatorname{LiF}(\sim 0.25 \mathrm{~nm})$ as hole blocking layer and aluminum $(\sim 100 \mathrm{~nm})$ as cathode were added. The resulting organic photovoltaic (OPV) devices were tested in air with a standard A.M $1.5 \mathrm{G}$ solar simulator for $I-V$ characters and external quantum efficiency (EQE) measurement was carried out by a Newport Cornerstone 260 Monochromator connected with a Newport 300 W Xenon light source.

\section{Results and Discussion}

3.1. Nozzle to Substrate Distance. Parameter control is the first step in developing this technology for any new polymer. Then, comparisons with standard spin-coating methods can be made between the thin films. From the basic structure of an airbrush in Figure 1, the carrier gas brings the polymer solution from a feed cup, along a needle that leads to the nozzle (dia. $0.18 \mathrm{~mm}$ in our case). Once the solution passes through the nozzle, a fine line composed of very small droplets will be generated and deposited on the substrate. In this process, a variety of parameters are correlated with the resulting thin film morphology $[12,13]$. These include the needlenozzle distance which determines the size of the spray spot (and density of droplets), the carrier gas pressure which controls the deposition rate, and the nozzle to substrate distance which determines the droplet drying time during flight. A detailed study on the nozzle to substrate distance was carried out in the first study in spray coating on OPV by Vak et al.

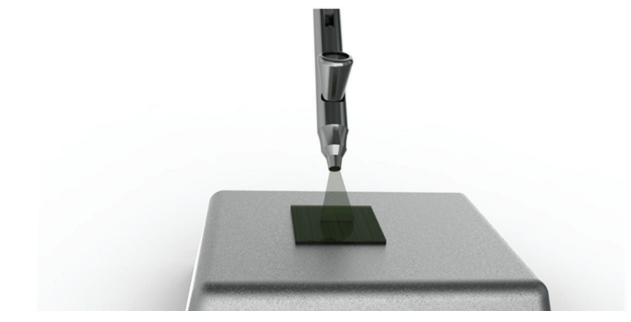

FIGURE 1: Airbrush spraying polymer on top of a device.

[12]. In that work, they defined the three regions between airbrush nozzle and substrate as "wet", "intermediate," and "dry" and they found the best linear control over thickness as a function of spraying time was in the "intermediate zone." They also suggested that the "intermediate zone" varied with the boiling point of the solvent used.

Initially, as a control, we fabricated devices using P3HT: PCBM as the absorbing layer and the performance was quit close to that reported elsewhere [10] and shown in Table 1 for the spray distance of $15 \mathrm{~cm}$. A detailed study was then carried out for our P1 polymer [14] and based on this, the "intermediate zone" was found to be very similar to the P3HT system; around $15 \mathrm{~cm}$, using the fixed solution made by dissolving $2.5 \mathrm{mg} \mathrm{P} 1$ and $5 \mathrm{mg}$ PCBM in DCB. We note that the DCB solution will dry the film slower than chlorobenzene due to the higher boiling point and therefore gives us a wider window for film thickness control [15].

3.2. Polymer Ink Properties. The properties of the spray solution not only affects the choice of nozzle-substrate distance for thickness optimization, but also plays an important role on film morphology. This is based primarily on the choice of solvent boiling point and vapor pressure. The basic concept is to choose a fast drying solvent to prevent droplets from redissolving sublayers but not so fast so as to allow for a homogenous and pin-hole free film to form. Green et al. [15] found chlorobenzene (CB) to be an excellent choice for a good film quality and achieved efficiencies $\sim 2.36 \%$ using P3HT : PCBM as the sprayed active layer. In 2009, Hoth et al. [16] adjusted the polymer solution viscosity by using a solvent mixture combining DCB and 1,3,5-trimethylbenzene in order to prevent the droplets from drying before touching the substrate as pristine $\mathrm{CB}$ does. This approach allowed for 


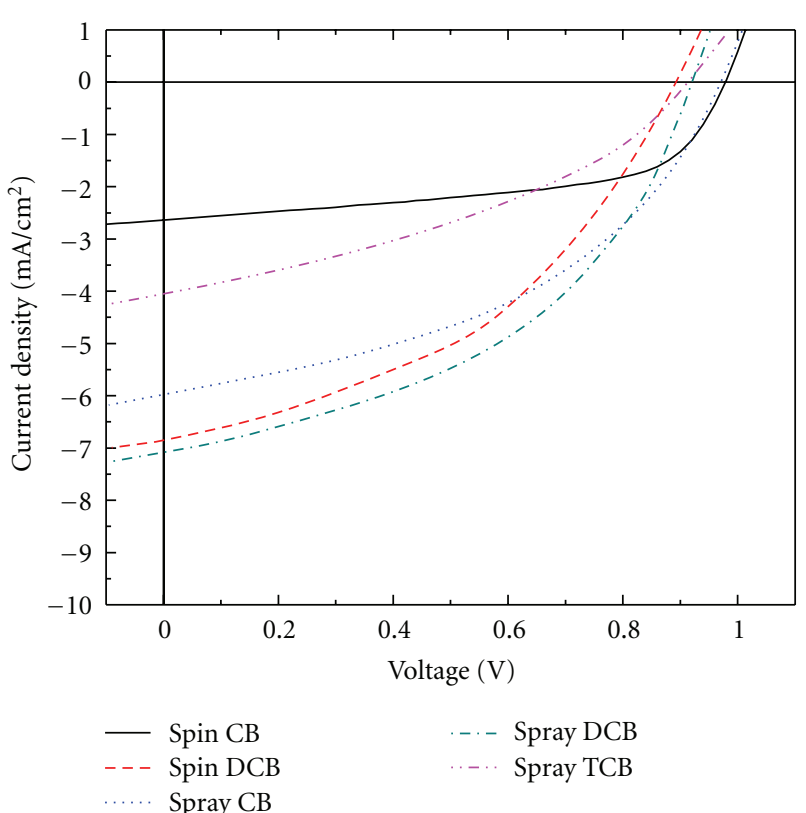

(a)

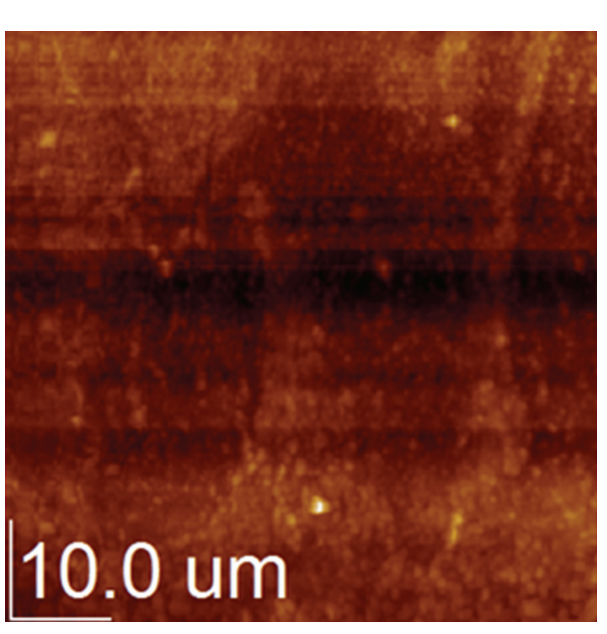

(c)

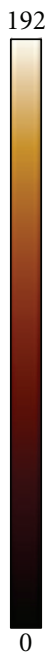

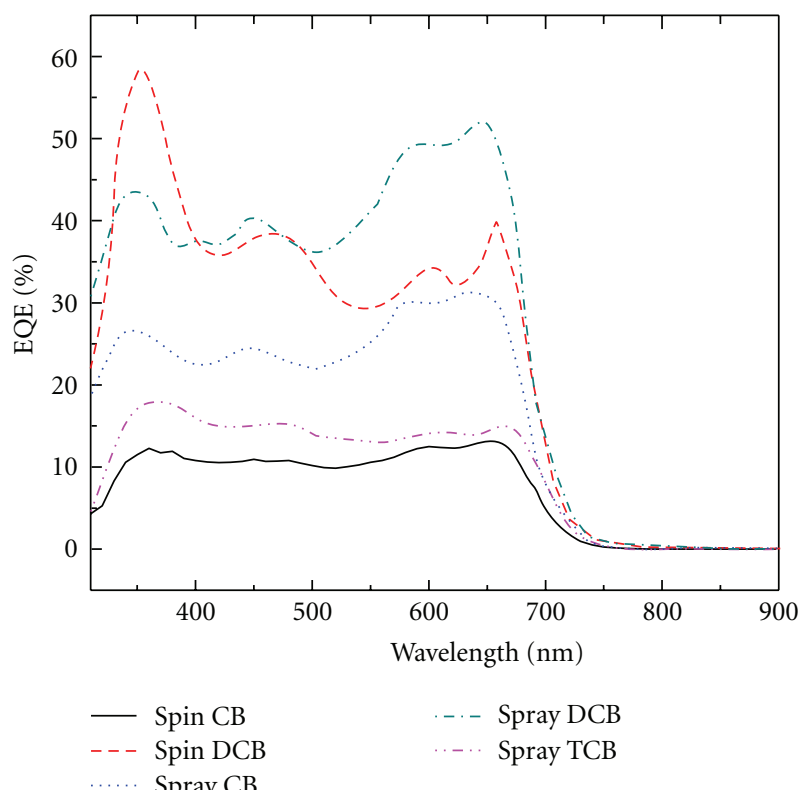

(b)

$10.0 \mathrm{um}$

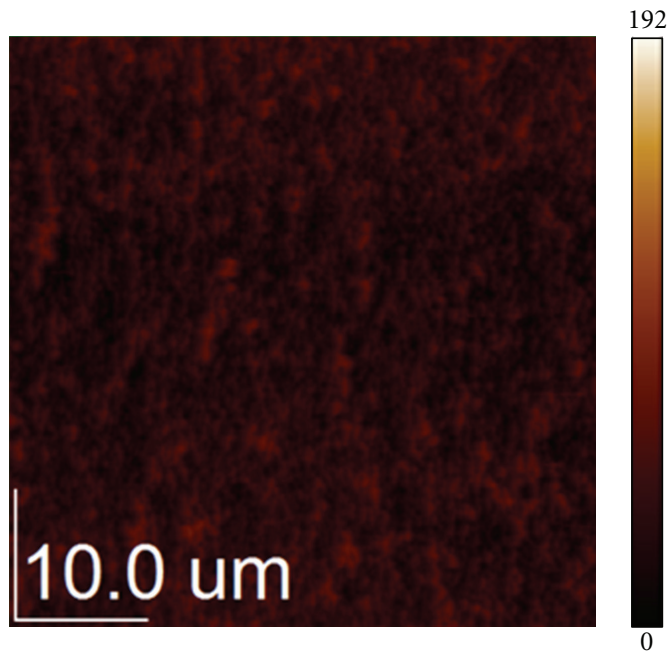

(d)

FIgURE 2: (a) $I-V$ character under illumination and (b) EQE for spin and spray-coated device using difference solvents; AFM images for (c) spray-coated and (d) spin-coated device; the scale bar for AFM is in units of nm.

efficiencies up to $3.1 \%$ in the same BHJ material system with the resulting reduced surface tension allowing for the formation of a preferred morphology. Very recently, Susanna et al. used the mixed solvent of DCB and $\mathrm{CB}$ to achieve a similar morphology and obtained a PCE 4.2\% [13].

However, the choice of solvent varies the solution viscosity, which is then related to the specific material to be sprayed. So it was necessary to determine the best solvent for the blended solution of $\mathbf{P 1}$ and $\mathrm{PC}_{61} \mathrm{BM}$. Considering both the solubility of the polymer and the boiling point (bp) (related to the drying rate) of the host solvent, we initially investigated three solvents: $\mathrm{CB}\left(\mathrm{bp}=131^{\circ} \mathrm{C}\right), \mathrm{DCB}(\mathrm{bp}=$ $\left.180.5^{\circ} \mathrm{C}\right)$, and $1,2,4$-trichlorobenzene $\left(\mathrm{TCB}, \mathrm{bp}=241.4^{\circ} \mathrm{C}\right)$.
The optimum ratio of $\mathbf{P 1}: \mathrm{PC}_{61} \mathrm{BM}$ was previously determined to be $1: 2$ and this was held constant for this study. Absorbing layers were sprayed at room temperature (RT) with constant volumes $(200 \mu \mathrm{L})$ and concentrations $(3.00 \mathrm{mg} / \mathrm{mL})$, yielding a film thickness of $90 \pm 33.5 \mathrm{~nm}$.

The current density-voltage $(J V)$ characteristics are summarized in Table 1. Active layers sprayed from DCB gave the best results with average power conversion efficiency (PCE) of $2.68 \%$, and a peak value of $3.00 \%$. Comparing to data from the devices sprayed from $\mathrm{CB}$ and TCB solution, we find that differences in performance are largely a result of differnces in short-circuit current density, which is $20 \%$ and $77 \%$ lower for the devices sprayed from CB and TCB, respectively. 


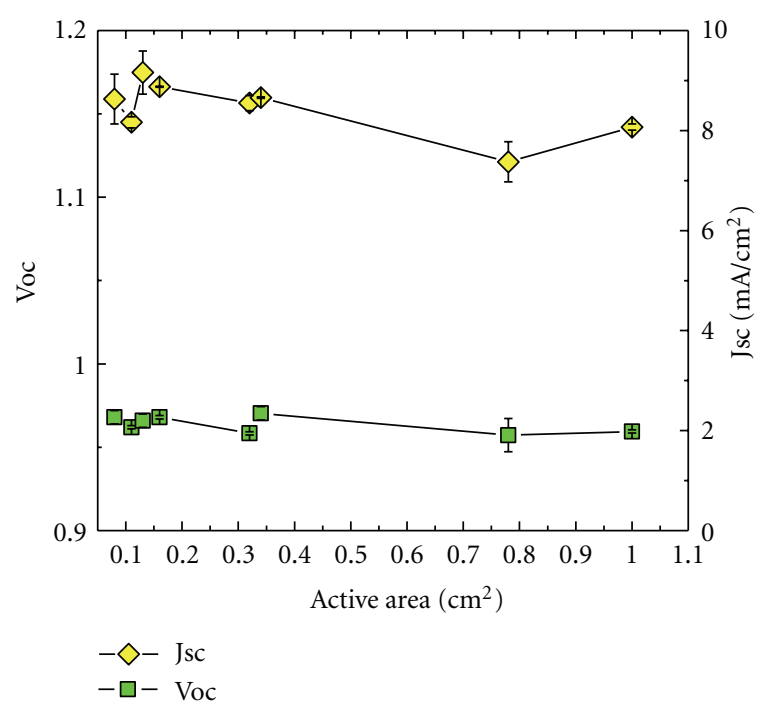

(a)

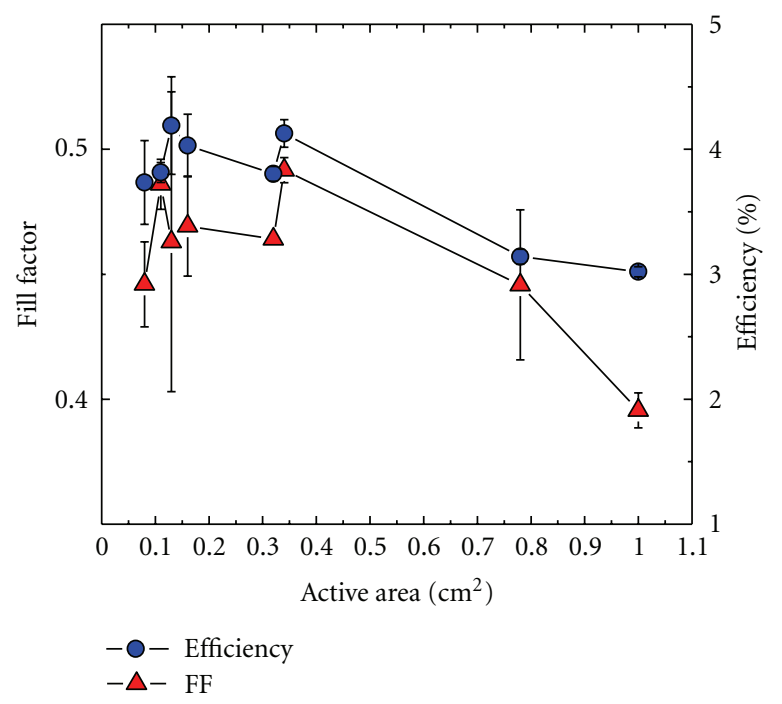

(b)

FIgURE 3: Statistical study with scale bars on (a) open-circuit voltage (Voc square) and short-circuit current (Jsc diamond). (b) Filling factor (triangle) and power conversion efficiency (circle) tested under a standard AM 1.5 solar simulator for sprayed devices as a function of active area.

Similar to our previous work with $\mathbf{P 1}$ we find that the fill factor $(\mathrm{FF})$ is higher for the devices sprayed from $\mathrm{CB}(\sim 0.455)$ compared with DCB $(\sim 0.405)$, though this difference is not significant enough to offset the Jsc difference.

Figure 2 shows the $J V$ curve under illumination and the corresponding external quantum efficiency and indicating that the performances are quite close between spin cast devices and sprayed devices. The slightly lower fill factor can be explained by observing in the atomic force microscopy (AFM) images of Figures 2(c) and 2(d), which show a similar morphology, but a much higher height variation for spraycoated films $(0 \sim 192 \mathrm{~nm})$ than spun cast films $(0 \sim 82 \mathrm{~nm})$ (refer to Figure 5 in the appendix). A variation in film

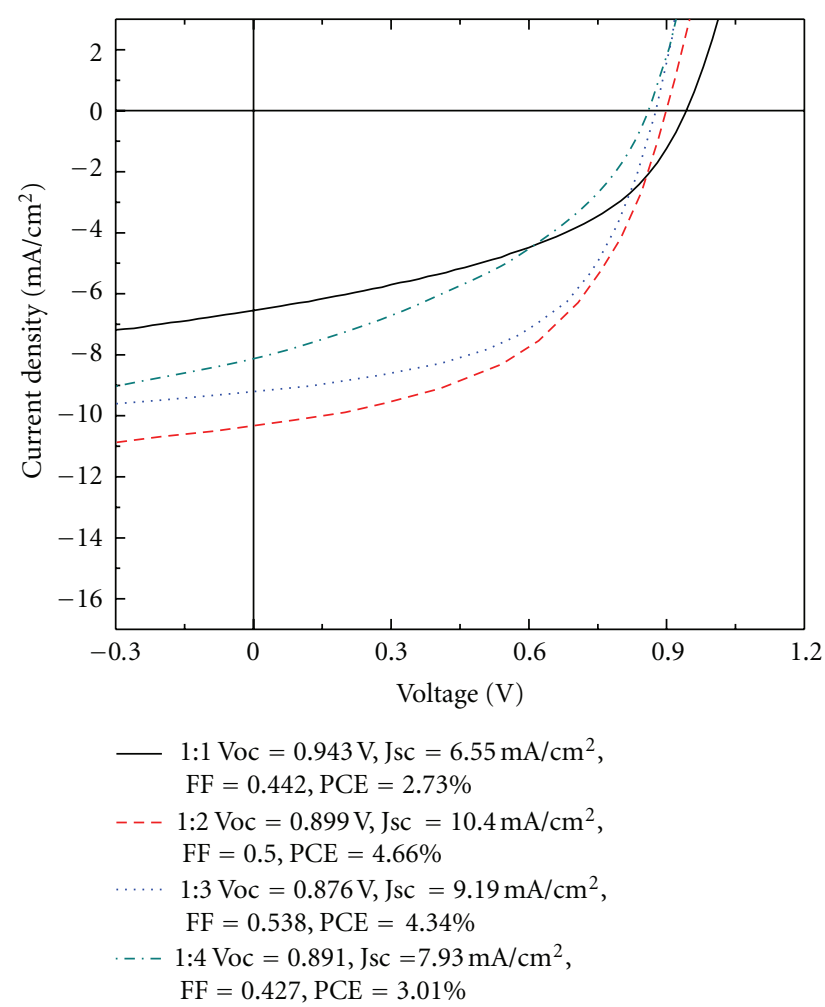

FIgURE 4: $J V$ characteristics under $100 \mathrm{~mW} / \mathrm{cm}^{2}$ illumination by standard A.M. 1.5 solar simulator with P1:PCBM ratio at $1: 1$ (black solid), $1: 2$ (red dash), $1: 3$ (blue dot), and 1:4 (green dashdot).

thickness and roughness will result in a charge recombination due to the limited charge mobility for conjugated polymers. Therefore, the thicker parts in the spray-casted film will lower the total shunt resistant and affect the device filling factors. However, this confirms that spray coating does present an approach to large-scale fabrication for OPV using this materials system.

3.3. Active Area. Researchers have also begun to focus on the realistic processes for larger area production. $\mathrm{Na}$ et al. [17] reported fully spray-coated, ITO-free, solar cells using the anode (PEDOT:PSS) and the active layer (P3HT:PCBM). They were able to achieve PCE $\sim 2.17 \%$, thereby moving towards a cost-effective deposition method. At the same time, Girotto et al. [11] have developed a physical model for understanding droplet dynamics. In this work, they were able to spray a uniform PEDOT: PSS followed by a spray-coated absorbing layer with a fill factor over 70\%, which is comparable to that achieved experimentally on spun-coated films. Taken together, these suggest that spray-coating can lead the OPV device to market without sacrificing efficiency but morphological considerations may be different from the spun cast approach.

However, we note that most of the studies $[11,12,15$, $18,19]$ for spray coating OPV were carried out with an active area of around $10 \mathrm{~mm}^{2}$ so scalability has not been 

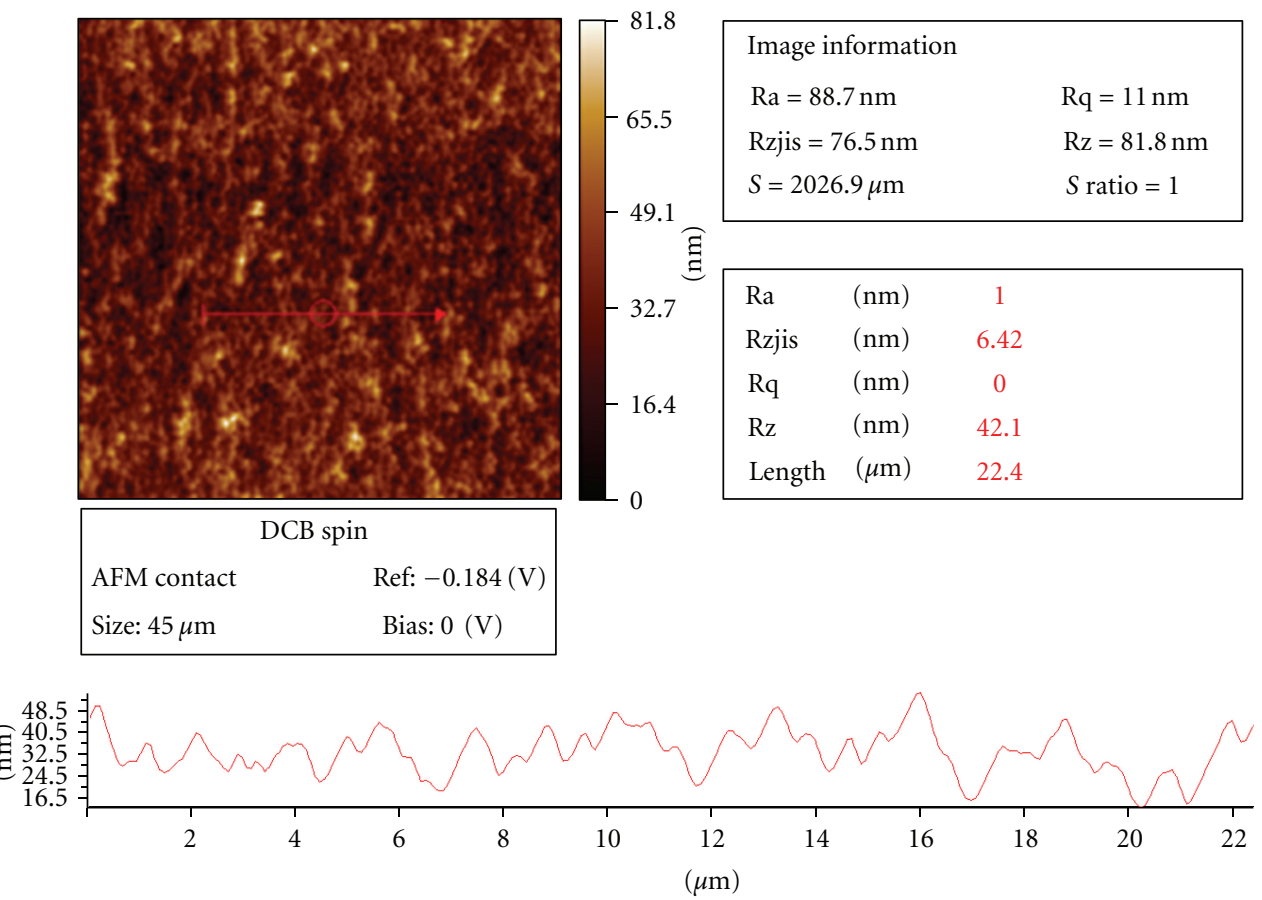

(a)
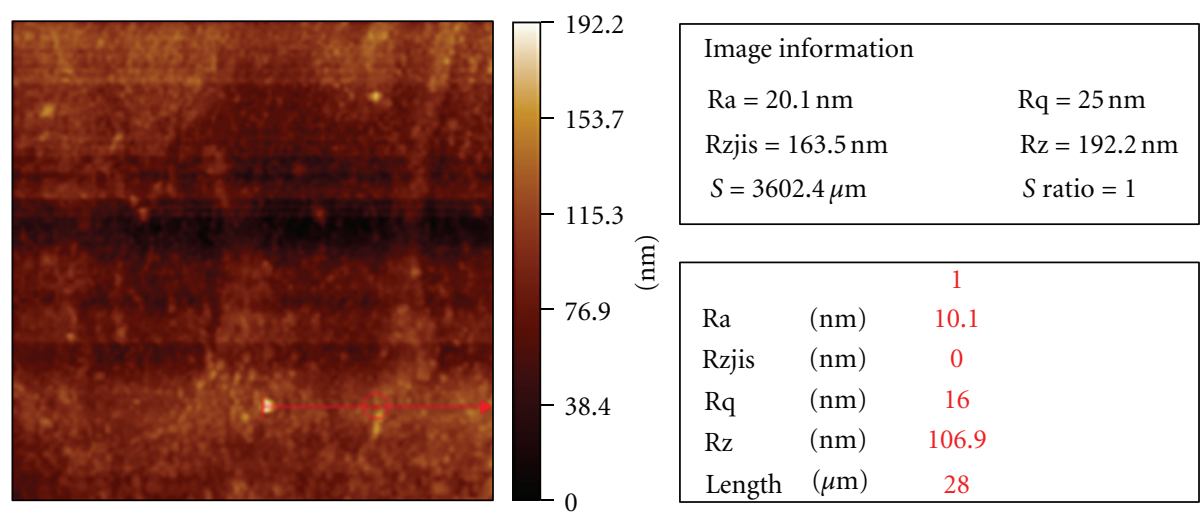

\begin{tabular}{|ll|}
\hline & Room temp \\
AFM contact & Ref: $0(\mathrm{~V})$ \\
Size: $60 \mu \mathrm{m}$ & Bias: $0(\mathrm{~V})$ \\
\hline
\end{tabular}

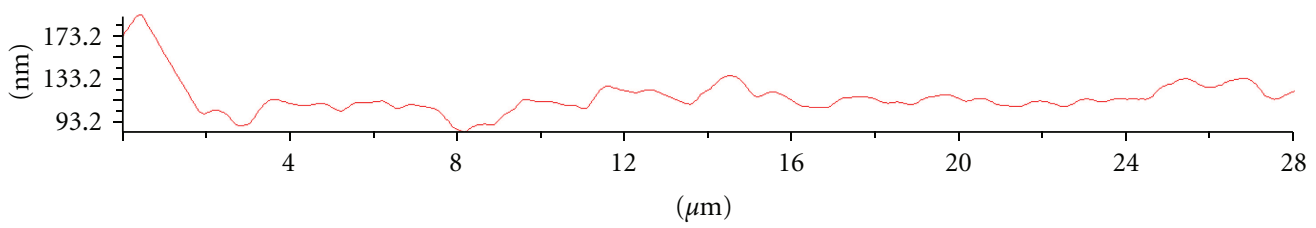

(b)

FIGURE 5: AFM topology analysis of (a) a spun-casted film and (b) a spray-casted film using DCB as carrier solvent.

demonstrated. Importantly, the roughness and thickness of sprayed films may reduce the final performance in large devices due to the increased internal resistance. In fact, it has been demonstrated that a $50 \%$ decrease occurs in a very large device (over $12 \mathrm{~cm}^{2}$ ) [20], whereas on a $4 \mathrm{~cm}^{2}$ device very little loss of performance (2.64\%) from the smaller devices was observed. In our study, we observed a $1 \%$ decrease as well when larger device sizes $\left(\right.$ to $1 \mathrm{~cm}^{2}$ ) were fabricated by spraying. This is due to the rougher surface.

In order to scale up our device by spray coating, we studied the $J V$ performance as a function of active area statistically in Figure 3. Each point in Figure 3 refers to the average 
over 8 electrodes ( 2 chips of 4 -electrode devices). Each electrode is an active area of the film. The error was estimated by the difference between the average and maximum. Again, the Voc is not affected by active area as shown in Figure 3 with voltages ranging from $0.957 \mathrm{~V}$ to $0.970 \mathrm{~V}$. Jsc is also relatively constant at $8.52 \pm 0.5 \mathrm{~mA} / \mathrm{cm}^{2}$ up to the active area of $34 \mathrm{~mm}^{2}$. It dropped to $0.45 \mathrm{~mA} / \mathrm{cm}^{2}$ when device sizes were increased to $100 \mathrm{~mm}^{2}$, which is only a $5 \%$ sacrifice in performance. The fill factor also decreased at $100 \mathrm{~mm}^{2}$ as expected to $0.395 \pm 0.007$ but the device with an active area of $34 \mathrm{~mm}^{2}$ still maintains a good fill factor of 0.49 that is comparable to the spun-casted devices. Because of the variation in thickness across the active are, the polymer solar cell can be viewed as a number of devices connected in parallel. When the active area increases, the shunt resistant was reduced from $853 \mathrm{ohm} \cdot \mathrm{cm}^{2}$ for the $0.3 \mathrm{~cm}$ device down to $585 \mathrm{ohm} \cdot \mathrm{cm}^{2}$ due to this film thickness variation which leads to charge recombination (AFM analysis is available in Figure 5 in the appendix). We suggest that this dominates the change in device filling factor. Surprisingly, the $100 \mathrm{~mm}^{2}$ devices show an average PCE of $3.02 \%$ in spraying coated devices. For such large active area devices this is quite good even though there is a $1.1 \%$ drop compared to the peak value of $4.12 \%$ for an active area of $34 \mathrm{~mm}^{2}$.

\section{Conclusion}

In summary, a review of the recent achievements in largescale OPVs (mainly based on P3HT: PCBM BHJ structures) by spray coating technology, has identified several important parameters such as nozzle-substrate distance, choice of solvent, mixture of cosolvent that influence morphology optimization. Using these parameters in this work, we have explored the possibility of fabricating solar cell devices by a hand-held airbrush with an active layer composed of a new low band gap copolymer poly $[(4,8-b i s$ (1-pentylhexyloxy)benzo[1,2- $\left.b: 4,5-b^{\prime}\right]$ dithiophene-2,6-diyl-alt-2,1,3-benzothiadiazole-4,7-diyl] and phenyl- $\mathrm{C}_{61}$-butyric acid methyl ester ( $\left.\mathrm{PC}_{61} \mathrm{BM}\right)$. 1,2-Dichlorobenzene is shown as an appropriate carrier solvent by comparing the solar cell performance with other two solvents (chlorobenzene, 1,2,4-trichlorobenzene) under identical conditions, and we obtain a promising PCE $3.00 \%$ on average without any special treatment under room temperature conditions. We believe these results may give some guidance to spray approaches in this class of donor acceptor polymers.

\section{Appendix}

See Figures 4 and 5.

\section{References}

[1] M. C. Scharber, D. Mühlbacher, M. Koppe et al., "Design rules for donors in bulk-heterojunction solar cells-towards $10 \%$ energy-conversion efficiency," Advanced Materials, vol. 18, no. 6, pp. 789-794, 2006.

[2] G. Yu, J. Gao, J. C. Hummelen, F. Wudl, and A. J. Heeger, "Polymer photovoltaic cells: enhanced efficiencies via a network of internal donor-acceptor heterojunctions," Science, vol. 270, no. 5243, pp. 1789-1791, 1995.

[3] J. Peet, J. Y. Kim, N. E. Coates et al., "Efficiency enhancement in low-bandgap polymer solar cells by processing with alkane dithiols," Nature Materials, vol. 6, no. 7, pp. 497-500, 2007.

[4] Y. Y. Liang, Z. Xu, J. B. Xia et al., "For the bright future-bulk heterojunction polymer solar cells with power conversion efficiency of 7.4\%," Advanced Materials, vol. 22, no. 20, pp. E135-E138, 2010.

[5] T. Y. Chu, J. Lu, S. Beaupré et al., "Bulk heterojunction solar cells using thieno[3,4- c ]pyrrole-4,6-dione and dithieno[3,2$\mathrm{b}: 2^{\prime}, 3^{\prime}-\mathrm{d}$ ] silole copolymer with a power conversion efficiency of 7.3\%," Journal of the American Chemical Society, vol. 133, no. 12, pp. 4250-4253, 2011.

[6] S. H. Park, A. Roy, S. Beaupré et al., "Bulk heterojunction solar cells with internal quantum efficiency approaching 100\%," Nature Photonics, vol. 3, no. 5, pp. 297-303, 2009.

[7] F. C. Krebs, M. Jørgensen, K. Norrman et al., "A complete process for production of flexible large area polymer solar cells entirely using screen printing-first public demonstration," Solar Energy Materials and Solar Cells, vol. 93, no. 4, pp. 422-441, 2009.

[8] F. C. Krebs, "Fabrication and processing of polymer solar cells: a review of printing and coating techniques," Solar Energy Materials and Solar Cells, vol. 93, no. 4, pp. 394-412, 2009.

[9] S. Kim, S. Na, J. Jo, G. Tae, and D. Kim, "Efficient polymer solar cells fabricated by simple brush painting," Advanced Materials, vol. 19, no. 24, pp. 4410-4415, 2007.

[10] L. M. Chen, Z. R. Hong, W. L. Kwan et al., "Multi-source/ component spray coating for polymer solar cells," ACS Nano, vol. 4, no. 8, pp. 4744-4752, 2010.

[11] C. Girotto, D. Moia, B. P. Rand, and P. Heremans, "Highperformance organic solar cells with spray-coated holetransport and active layers," Advanced Functional Materials, vol. 21, no. 1, pp. 64-72, 2011.

[12] D. Vak, S. S. Kim, J. Jo et al., "Fabrication of organic bulk heterojunction solar cells by a spray deposition method for low-cost power generation," Applied Physics Letters, vol. 91, Article ID 081102, 3 pages, 2007.

[13] G. Susanna, L. Salamandra, T. M. Brown, A. Di Carlo, F. Brunetti, and A. Reale, "Airbrush spray-coating of polymer bulkheterojunction solar cells," Solar Energy Materials and Solar Cells, vol. 95, no. 7, pp. 1775-1778, 2011.

[14] W. Nie, C. M. MacNeill, Y. Li, R. E. Noftle, D. L. Carroll, and R. C. Coffin, "A soluble high molecular weight copolymer of benzo[1,2-b:4,5-b'] dithiophene and benzoxadiazole for efficient organic photovoltaics," Macromolecular Rapid Communications, vol. 32, no. 15, pp. 1163-1168, 2011.

[15] R. Green, A. Morfa, A. J. Ferguson, N. Kopidakis, G. Rumbles, and S. E. Shaheen, "Performance of bulk heterojunction photovoltaic devices prepared by airbrush spray deposition," Applied Physics Letters, vol. 92, no. 3, Article ID 033301, 2008.

[16] C. N. Hoth, R. Steim, P. Schilinsky et al., "Topographical and morphological aspects of spray coated organic photovoltaics," Organic Electronics: Physics, Materials, Applications, vol. 10, no. 4, pp. 587-593, 2009.

[17] S. I. Na, B. K. Yu, S. S. Kim et al., "Fully spray-coated ITO-free organic solar cells for low-cost power generation," Solar Energy Materials and Solar Cells, vol. 94, no. 8, pp. 1333-1337, 2010.

[18] K. Kawano, J. Sakai, M. Yahiro, and C. Adachi, "Effect of solvent on fabrication of active layers in organic solar cells based on poly(3-hexylthiophene) and fullerene derivatives," Solar Energy Materials and Solar Cells, vol. 93, no. 4, pp. 514-518, 2009. 
[19] C. Girotto, B. P. Rand, J. Genoe, and P. Heremans, "Exploring spray coating as a deposition technique for the fabrication of solution-processed solar cells," Solar Energy Materials and Solar Cells, vol. 93, no. 4, pp. 454-458, 2009.

[20] S. Y. Park, Y. J. Kang, S. Lee et al., "Spray-coated organic solar cells with large-area of $12.25 \mathrm{~cm}^{2}$," Solar Energy Materials and Solar Cells, vol. 95, no. 3, pp. 852-855, 2011. 


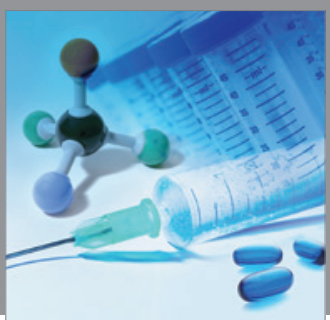

International Journal of

Medicinal Chemistry

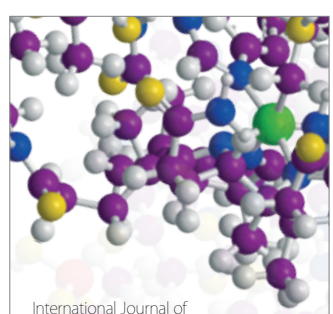

Carbohydrate Chemistry

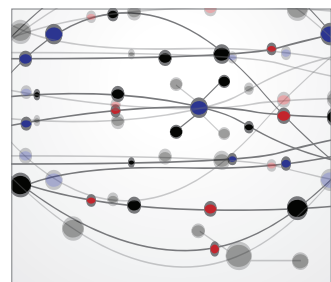

The Scientific World Journal
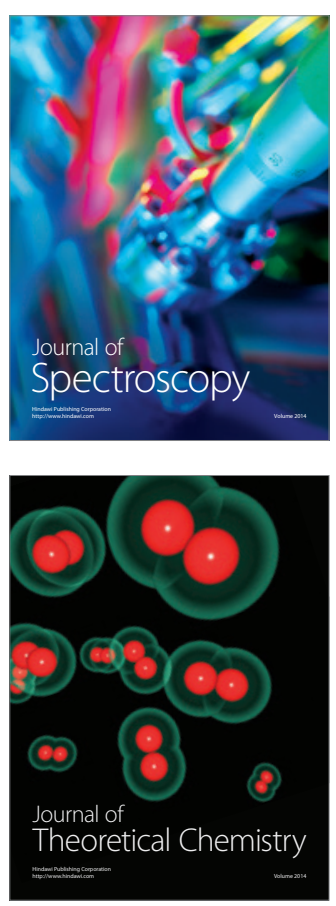
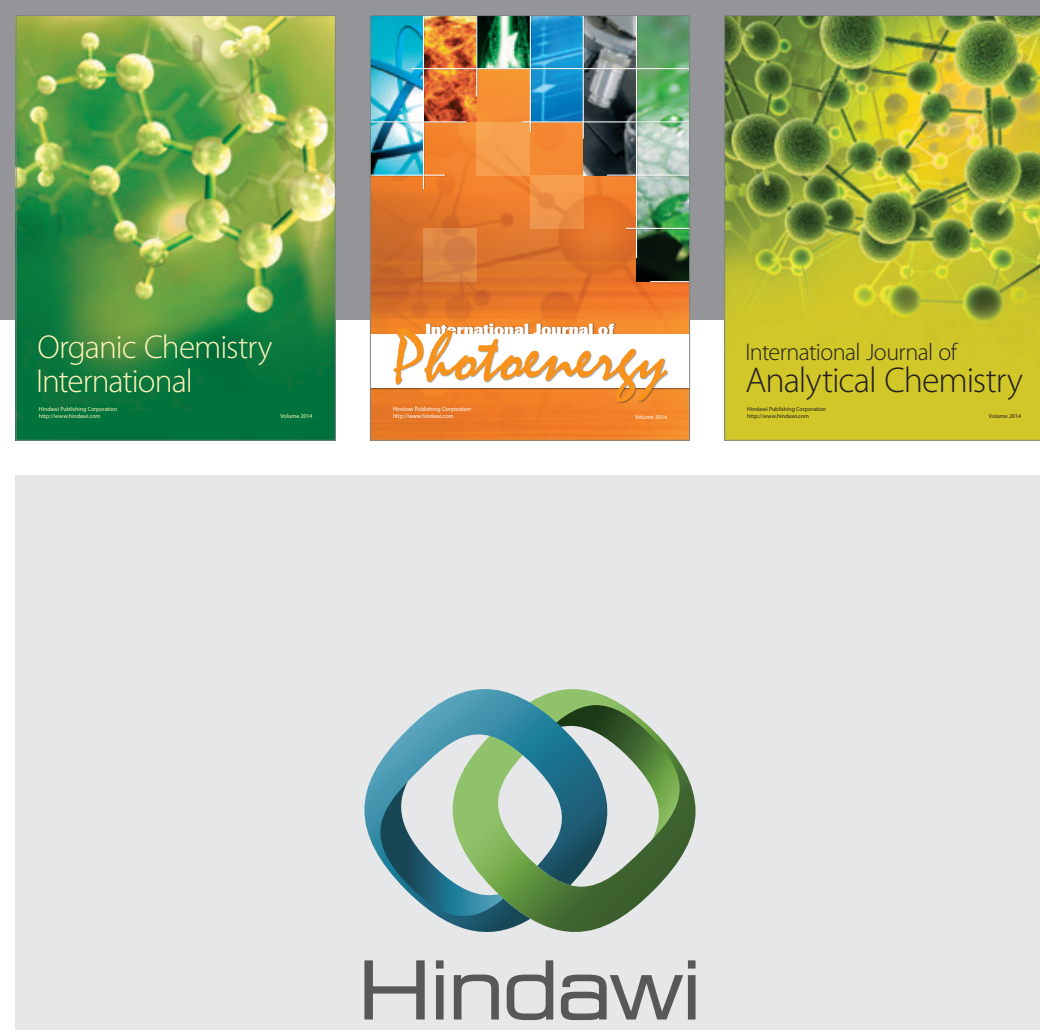

Submit your manuscripts at

http://www.hindawi.com
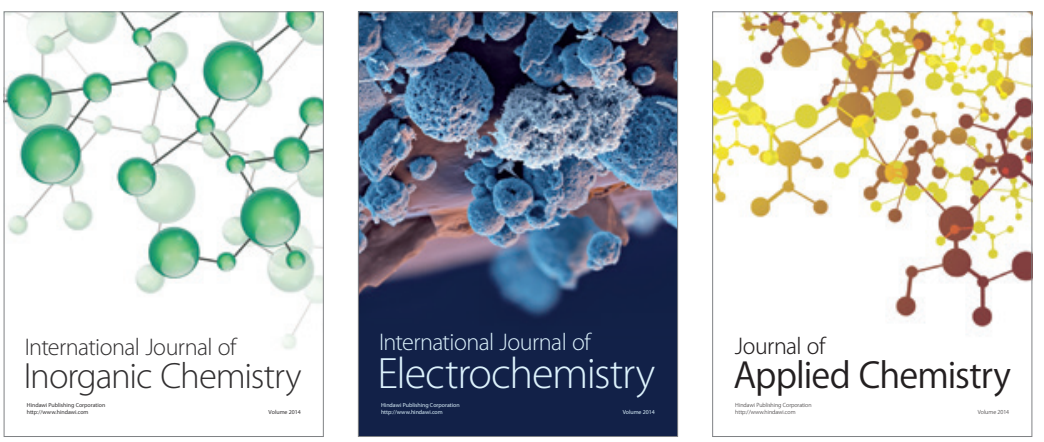

Journal of

Applied Chemistry
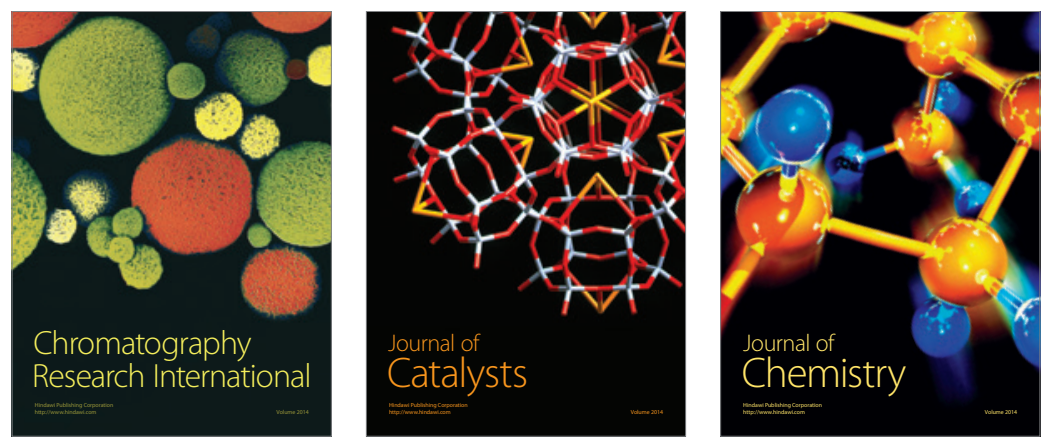
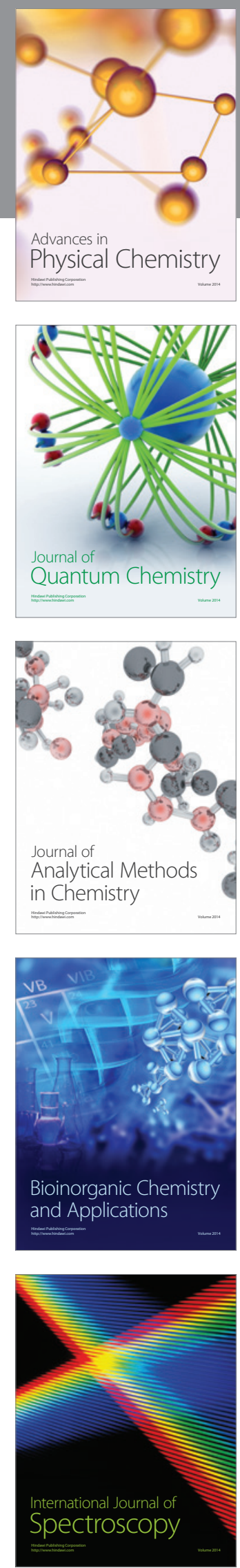